\title{
APLICAÇÃO DO GEOPROCESSAMENTO NAAVALIAÇÃO E ESPACIALIZAÇÃO DAS PERDAS FÍSICAS DE ÁGUA DO SISTEMA DE ABASTECIMENTO PÚBLICO DE RONDONÓPOLIS - MT
}

\section{Application of the Geographic Information Systmems in the evalution and spatial distribuition of the physical losses of the System of Water Public Supplying of Rondonópolis - MT}

Jeater Waldemar Maciel Correa Santos

Professor Adjunto III do Departamento de Geografia da Universidade Federal de Mato Grosso - Campus de Rondonópolis jeater@ufmt.br

Artigo recebido para publicação em 08/03/2007 e aceito para publicação em 20/04/2007

RESUMO: O presente estudo teve como objetivo investigar os níveis de perdas físicas de água do sistema de abastecimento de Rondonópolis, que é operado pela concessionária municipal "Serviço de Saneamento Ambiental de Rondonópolis - SANEAR". Para tanto foram utilizados dados de produção e consumo de água em Rondonópolis, referentes ao período de 1998 a 2003, fornecidos pelo SANEAR em nível das zonas de produção de água da cidade. Através de análises estatísticas e recursos de geoprocessamento, foram avaliados e espacializados os índices de perdas físicas de água desse sistema, e a ocorrência de variações sazonais nos níveis de consumo de água. Como principais resultados, verificaram-se: a) a estacionalidade nos níveis de consumo de água da cidade, sendo que no período compreendido entre os meses de janeiro a abril este fica 5\% a baixo da média anual e no período de agosto a dezembro, 5\% a cima desta média; b) ocorrência de índices elevados de perdas físicas de água no sistema de abastecimento de Rondonópolis os quais superaram a 50\% na maioria das 16 zonas de produção de água da cidade, e em duas delas chegaram a cerca de 90\%. Na média as perdas de água foram de $55 \%$ para os dois anos analisados, ou seja, superando os índices de perdas verificados em nível Nacional (40\%) e da Região Centro-Oeste (44\%).

Palavras-chave: Sistema de Abastecimento de Água, Geoprocessamento, Saneamento Básico

ABSTRACT: The study had as objective to investigate the levels of physical losses of water of the supplying system of Rondonópolis-MT operated by the concessionaire Service of Ambient Sanitation of Rondonópolis - SANEAR. The data used for this study are of production and consumption of water in Rondonópolis, in the period of years of 1998 the 2003, supplied by SANEAR for the level of the zones of water production of the city. Through statistical analyses and resources of Geographic Information Systems, this data has been used for to evaluate and to distribute in the Rondonópolis space the rate of physical losses of water of this system and to identify seasonal variations of the levels of water consumption. As main results, they had been verified: a) verification of the seasonal variations in the levels of water consumption of the city being it 
$5 \%$ below of the annual average in the period between the April and January months and 5\% above of this average in the period of August the December; b) verification of high rate of physical losses of water in the supplying system of Rondonópolis which exceed $50 \%$ in the majority of the 16 zones of water production of the city and in two of them had arrived about $90 \%$. In average the losses of water had been of 55\% in Rondonópolis for the two analyzed years, exceeding the average rate of Brazil (40\%) and of the Center-West Region (44\%) of losses of invoicing (PMSS, 2004:19).

Keywords: System of Water supply, Basic Sanitation, Geographic Information Systems

\section{INTRODUÇÃO}

Apesar do Brasil ser um país rico em recursos hídricos de superfície e subterrâneos, a distribuição dos mesmos ao longo do território nacional não é homogênea, e muito menos de forma proporcional às concentrações de sua população. Como destaca Branco (2002:241) “.... as regiões de maior demanda de água potável são também as que menos dispõem de mananciais caracterizados por qualidade compatível com esse uso".

O fornecimento de água em quantidade e qualidade adequadas é de fundamental importância para garantir a sustentabilidade sócio-ambiental dos espaços urbanos, seja para atender as demandas de seus sistemas produtivos ou das necessidades de saneamento básico de seus habitantes. Pois, conforme dados citados no relatório da Agenda 21 apud Hespanhol (2002:251) “aproximadamente 80\% de todas as doenças de origem hídrica e mais que um terço das mortes em paises em desenvolvimento, são causadas pelo consumo de água contaminada e que, em média, um décimo do tempo produtivo de cada pessoa é sacrificado a essas doenças”.

Segundo dados do Diagnóstico dos Serviços de Água e Esgotos do Brasil do ano de 2003 (PMSS, 2004), a “indústria do saneamento básico” no país é composta por 318 prestadores de serviços dos quais cerca de $84 \%$ são de natureza jurídica pública, classificados ainda, conforme a abrangência dos serviços que prestam, em prestadores abrangência regional (25), abrangência microrregional (8) e de serviço local (285). Destaca-se que deste último grupo, 91,6\% são de direito público, representados, sobretudo, por autarquias municipais.

Tal indústria, aplicando tarifas de água que variaram entre 0,98 e 1,42 reais por metro cúbico disponibilizado, obteve em 2003, uma receita de 15,5 bilhões de reais, dos quais, cerca de $82 \%$ correspondendo a parcela dos prestadores de serviço de abrangência regional, 17,5\% aos de abrangência local e $0,5 \%$ aos de abrangência microrregional. Ressaltando-se que cerca de $68 \%$ dos prestadores de serviço de abrangência local tiveram neste ano, receitas superiores às despesas totais com serviços (PMSS, 2004:12-15), o que permitiria a realização de investimentos em seus sistemas a fim de melhorar a eficiência dos mesmos.

Conforme explica Turolla apud Silva (2005:01), tal indústria tem como característica relevante a presença de custos fixos elevados em capital altamente específico, razão pela qual a mesma se identifica como um monopólio natural, favorecendo a sua baixa eficiência produtiva, uma vez que não enfrenta competição direta. Por outro lado o consumidor também fica numa situação difícil, pois muitas vezes recebe um serviço de baixa qualidade (marcado por falta de água e/ou interrupções temporárias no fornecimento desta, águas fora do padrão de potabilidade determinado pelos órgãos de saúde etc) com tarifas elevadas e não tem como recorrer a outro fornecedor desse produto.

O índice de perdas de água de um sistema 
de abastecimento público é um dos principais indicadores de sua eficiência. E no caso específico das perdas físicas, sua redução implica em maior aproveitamento desse recurso natural, menos investimentos na produção de água (já que será requerido menos insumos, sobretudo produtos químicos e energia elétrica), aumento da receita tarifária e redução dos níveis de desperdício por força da aplicação da tarifa aos volumes efetivamente consumidos (BRASIL, 1998).

Com a preocupação de reduzir o nível de desperdício de água nos centros urbanos do Brasil, o Governo Federal iniciou em 1993 o Programa Nacional de Combate ao Desperdício de Água (PNCDA), juntamente com a publicação de uma série de documentos técnicos de apoio (DTA), dos quais o DTA A2 trata especificamente do combate das perdas nos sistemas de abastecimento público (BRASIL, 1998)

O Serviço Nacional de Informações sobre Saneamento (SNIS), utiliza como indicador de perdas de água em sistemas de abastecimento urbanos no Brasil as perdas de faturamento, medida pela relação entre os volumes faturados e disponibilizados para distribuição. Assim, considerando-se todo o conjunto de prestadores de Serviços de água e esgotos no Brasil para o ano de 2003, tais perdas variaram em média entre 25,6 e 40,5\% segundo abrangência regional do prestador de serviço e na média geral ficaram em 39,4 \% . (PMSS, 2004:19).

Considerando-se que o nível médio das perdas de faturamento fica em torno de $17 \%$ em diversas regiões do mundo, e que em países como Alemanha, Suíça, Países Baixos e Singapura, ele fica abaixo de $10 \%$, percebe-se que é preciso que o governo brasileiro realmente realize muitos esforços para combater esse problema no país. (BRASIL, 1998:38)

Deve-se ressaltar que índices elevados de perdas físicas nos sistemas de abastecimento de água, também indicam baixa qualidade do serviço prestado, normalmente marcado por alta freqüência de parali- sações e/ou intermitências no abastecimento de água, as quais promovem sérias implicações sociais e de saúde na população atendida pelo sistema, particularmente nas áreas periféricas e bairros de baixa renda (HESPANHOL, 2002).

O município de Rondonópolis, que tem seu abastecimento de água e coleta de esgotos realizados por prestador de serviço de nível local, apresenta elevado índice de perdas de água em 2003, fazendo com que seja produzido anualmente em torno de $19.000 .000 \mathrm{~m}^{3}$ para atender um consumo de apenas cerca de $7.000 .000 \mathrm{~m}^{3}$. Já em relação as perdas de faturamento, nesse ano elas ficaram em 56,1\% em Rondonópolis, ou seja, bem acima da média nacional para prestadores de abrangência local que é de $40 \%$ (PMSS, 2004).

Buscando identificar os motivos da constante falta de água em diversos bairros de Rondonópolis no final da década de 90, Garcia (1995) já apontava que o grande problema do sistema de abastecimento de água na cidade, devia-se a perdas físicas da rede de distribuição. E que isto em parte isso decorria da utilização nessa rede de tubulações muito velhas (com tempo utilização a cima do tempo de vida útil recomendado) e, em alguns segmentos, tubulações fabricadas com materiais ultrapassados e de baixa resistência,

Outro fator que pode estar contribuindo para o elevado índice de perdas físicas do sistema de abastecimento de água de Rondonópolis, é o fato dos valores de produção de água serem mantidos constantes durante todo o ano pela concessionária, desconsiderando-se possíveis flutuações sazonais desse consumo. Pois, no caso de haver um período do ano em que o nível de consumo seja menor, a pressão na rede será maior durante o mesmo, elevando o nível de perdas físicas no sistema em decorrência de rompimentos e vazamentos na mesma.

Um dos grandes problemas dos estudos que visam a previsão de longo prazo da demanda urbana e a otimização dos serviços dos sistemas de abastecimento de água é a subestimação de suas variações 
sazonais. Pois: "as variações climáticas tem um peso grande na determinação de padrões específicos de demanda e seu estudo sistemático associado à demanda é muito raro”. (BRASIL, 1999: 11)

Em razão dos problemas apontados para o Sistema de Abastecimento Público de Água de Rondonópolis, desde o ano de 2004 está sendo desenvolvido no Laboratório de Geoprocessamento do Departamento de Geografia da Universidade Federal de Mato Grosso em Rondonópolis, o estudo intitulado "Ritmo Climático e Consumo de Água em Rondonópolis no período de 1997 a 2003”, que busca através de seus resultados, fornecer subsídios para a resolução dos mesmos.

Assim, este artigo tem como objetivo divulgar parte dos resultados desta pesquisa, mais especificamente os relativos à avaliação e espacialização das perdas de água deste Sistema de Abastecimento Público e a verificação da hipótese de uma possível variação sazonal nos níveis de consumo de água na cidade.

\section{ORIGENS DAS PERDAS DE ÁGUA EM SISTEMAS DE ABASTECIMENTO}

Em sistemas públicos de abastecimento, do ponto de vista operacional, as perdas de água são consideradas correspondentes aos volumes não contabilizados. Esses englobam tanto as perdas físicas que representam a parcela de água não consumida, como as não físicas, que correspondem a água consumida e não registrada (BRASIL, 1998:33).

\section{Perdas Físicas}

As Perdas Físicas representam a parcela não consumida da água produzida pelo sistema. Elas originam-se sobretudo, de vazamentos no sistema, os quais envolvem operações realizadas nas fases de captação, adução de água bruta, tratamento, reservação, adução de água tratada e principalmente a distribuição (QUADRO 1). Também compõem tais perdas, procedimentos operacionais do sistema como lavagem de filtros e descargas na rede, quando estes provocam consumos superiores ao estritamente necessário para a operação. Correspondem ainda, "as perdas nas economias de consumo, correspondendo àquelas que ocorrem no interior das edificações, em razão não apenas de vazamentos mas também de mal uso" (SILVA et al. apud SILVA, 2005:02).

A redução das perdas físicas permite dimi-

Quadro 1. Perdas Físicas em Sistemas de Abastecimento de água nas Etapas, Origem e Magnitude

\begin{tabular}{l|l|l}
\hline $\begin{array}{l}\text { Etapa do Sistema de } \\
\text { Abastecimento de Água }\end{array}$ & Origem da Perda & Magnitude \\
\hline Adução de água bruta & $\begin{array}{l}\text { Vazamentos nas tubulações } \\
\text { Limpeza do poço de sucção }\end{array}$ & $\begin{array}{l}\text { Variável, função do estado das tubulações e da } \\
\text { eficiência operacional }\end{array}$ \\
\hline Tratamento de Água & Vazamentos estruturais & $\begin{array}{l}\text { Significativa, função do estado das instalações } \\
\text { e da eficiência operacional }\end{array}$ \\
& $\begin{array}{l}\text { Lavagem de filtros } \\
\text { Descarga de lodo }\end{array}$ & Variável, função do estado das instalações e da \\
& Vazamentos estruturais & eficiência operacional \\
\hline Reservação & Extravasamentos & Variável, função do estado das tubulações \\
& Limpeza de Reservatórios & principalmente das pressões \\
\hline Adução de Água Tratada & Vazamentos nas tubulações & \\
\hline Distribuição & Limpeza do poço de sucção & Significativa, função do estado das tubulações \\
& Descargas & e principalmente pressões
\end{tabular}

Fonte: BRASIL, 1998:41

Sociedade \& Natureza, Uberlândia, 19 (2): 51-67, dez. 2007 
nuir os custos de produção uma vez que implicam diretamente na redução do consumo de energia elétrica, de produtos químicos entre outros, o que também resulta em menores tarifas dos serviços para os consumidores.

\section{Perdas Não Físicas}

Já as Perdas Não Físicas originam-se de ligações clandestinas ou não cadastradas, hidrômetros parados ou que submedem, fraudes em hidrômetros e outras. Também são denominadas de perdas de faturamento, uma vez que seu principal indicador é a relação entre o volume disponibilizado e o volume faturado.

Portanto, o combate a perdas ou desperdícios implica na redução do volume de água não contabilizado, e consequentemente na adoção de medidas para reduzir as perdas físicas e não físicas do sistema.

\section{Avaliação das Perdas de Água em Sistemas de Abastecimento}

De acordo com Brasil (1998) a estimativa das perdas de água em um sistema de abastecimento se da por meio da comparação entre o volume de água transferido de um ponto do sistema e o volume recebido em ou mais pontos do sistema situados na área de influência do ponto de transferência. $\mathrm{E}$ a identificação e separação das perdas físicas de água das não físicas é tecnicamente possível mediante pesquisa de campo utilizando-se a metodologia da análise de histograma (registros contínuos) de consumo das vazões macromedidas. Contudo, segundo este documento, há indícios de que em sistemas com índice de micromedição próximo a $100 \%$, as ligações clandestinas possuem pouca relevância, sendo as perdas mais significativas àquelas decorrentes das perdas físicas. Desse modo, quando este for o caso, essas devem ser o foco principal de atuação para a redução de perdas em sistemas públicos de abastecimento.

A avaliação de perdas de água em sistemas de abastecimento deve ser realizada levando-se em consideração os subsistemas integrantes do processo de produção, no que se refere à comparação das quantidades de matéria-prima (água bruta) com o produto (água tratada), e distribuição, no que tange ao produto (água tratada ofertada), cotejado com o consumo (BRASIL, 1998). Deste modo, é importante que os operadores do sistema disponham de dados de medidas realizadas nestas diferentes fases/ etapas do processo de produção, distribuição e consumo de água, o que muitas vezes não é a realidade. Tais dados, quando existentes, permitem o estabelecimento de cálculos de indicadores de desempenho da eficiência do sistema, tais como: a) índice de perda física na produção (PFP); b) índice de perda física na adução (PFA); c) índice de perda física no tratamento (PTR); d) índice de perda física na distribuição (PFD). Este último relaciona o volume fisicamente utilizado (VFU) com o volume disponibilizado (VD), englobando assim, tanto as perdas físicas como não físicas.

Do ponto de vista comercial e financeiro, outro indicador importante de avaliação do processo de comercialização e distribuição da água é o Índice de Perda de Faturamento (IPF), ou Água Não Faturada (ANF), que corresponde a diferença entre o volume disponibilizado (VD) e o volume faturado (VF) sobre o volume disponibilizado (BRASIL, 1998). Contudo, é preciso ressaltar a complexidade do conceito de faturamento da água em nosso país, pois além de ser comum a adoção por parte das concessionárias, para fins de faturamento e emissão da conta de água, de um consumo mínimo (da ordem de $10 \mathrm{~m} 3 / \mathrm{mês}$ ), a tarifa de água normalmente tem seu preço escalonado segundo faixas de consumo de água. Assim, o custo total do consumo de uma conta referente a $35 \mathrm{~m}^{3}$ de água, por exemplo, será composto pela soma do valor do total consumido entre 30 e $40 \mathrm{~m}^{3}$, que será mais caro que o total referente ao consumo realizado entre 20 e $30 \mathrm{~m}^{3}$, que por sua vez também será mais caro que o custo dos primeiros $10 \mathrm{~m}^{3}$ de água.

Desse modo, apesar de no Brasil ser comum a utilização dos índices de perdas de faturamento como indicador de desempenho dos sistemas públicos 
de abastecimento, esse indicador não expressa necessariamente as perdas em volumes físicos (SILVA, 2005).

Outro indicador muito utilizado para avaliar a eficiência dos sistemas públicos de abastecimento de água é o índice de perdas por quilômetro de rede. Contudo, a dificuldade normalmente encontrada pelas concessionárias para utilização desse indicador é a obtenção de medidas confiáveis da extensão das redes de distribuição dos sistemas (BRASIL, 1998).

\section{Avaliação de Perdas Físicas de Água em Sistemas de Distribuição}

Nos sistemas de distribuição as perdas físicas de água são decorrentes basicamente de perdas que ocorrem durante operações do sistema e por vazamentos na rede e nos ramais prediais.

As perdas operacionais como o próprio nome diz são aquelas associadas à operação do sistema. Estas podem estar disfarçadas sob a forma de usos úteis no processo produtivo (como água de lavagem de filtros) e nos procedimentos operacionais (como descargas para melhoria da qualidade da água em redes, e água usada para limpeza de reservatórios), ou ainda na forma de falhas evidentes (como extra- vasamentos de reservatórios). Tais perdas podem ser importantes em termos volumétricos e sua redução, em alguns casos, envolve apenas mudanças de procedimentos e melhorias operacionais com pequenos ou nenhum investimento (BRASIL, 1998).

Já as perdas por vazamentos, são decorrentes de rupturas em adutoras, subadutoras, redes e ramais prediais, falhas em conexões e peças especiais, trincas nas estruturas e falhas na impermeabilização das ETA e reservatórios.

\section{O SISTEMA DE ABASTECIMENTO DE ÁGUA DE RONDONÓPOLIS - MT}

O município de Rondonópolis, localiza-se na região sudeste do Estado de Mato Grosso a cerca de 200 km da capital Cuiabá. Grosso modo, tem seus limites enquadrados pelas seguintes coordenadas geográficas: $16^{\circ} 00^{`}$ e $17^{\circ} 06^{`}$ de latitude sul e $54^{\circ} 13^{`}$ e $55^{\circ} 02^{`}$ de longitude oeste. (FIG 01)

O serviço de abastecimento público de água em Rondonópolis, teve início no ano de 1962 quando a Prefeitura Municipal solicitou a Fundação SESC o perfuramento do primeiro poço tubular profundo (denominado PT1) na área central da cidade (GARCIA, 1995).

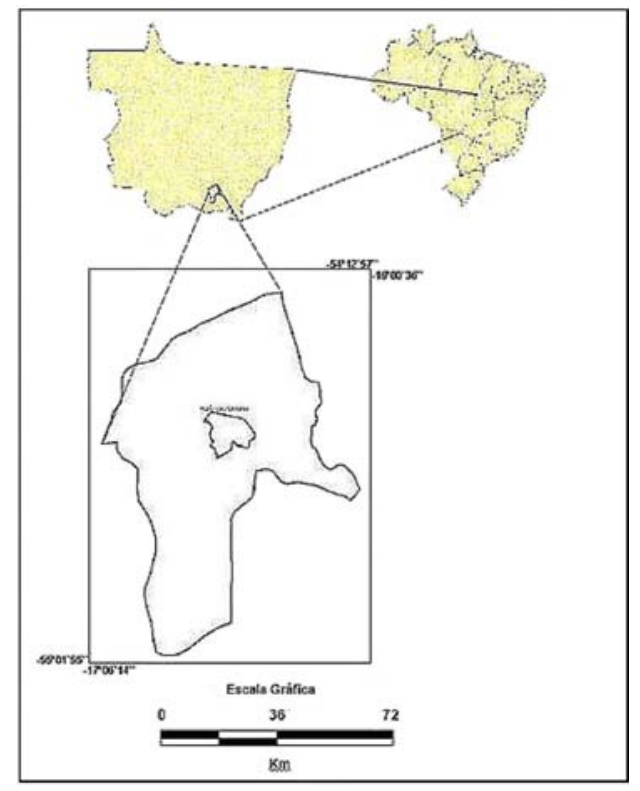

Figura 1. Localização do município de Rondonópolis - MT. 
Apesar de Rondonópolis ser cortada pelo Rio Vermelho, que é um rio perene e com grande volume de água, o serviço de abastecimento público de água da cidade iniciou com a exploração do manancial subterrâneo, sendo que apenas no ano de 1981 foi construída a estação de tratamento de água coletada no Rio Vermelho (GARCIA, 1995), tornando misto o sistema de captação de água para abastecimento público em Rondonópolis, ou seja, captando água tanto de manancial superficial quanto subterrâneo.

Em 1965 o poder público municipal cria uma autarquia, o Serviço Autônomo de Água e Esgoto SAE, que era administrado por uma parceria entre a Prefeitura Municipal de Rondonópolis e a Fundação SESC. Entretanto, em 1975 a Prefeitura Municipal firma um contrato de concessão com o Estado de Mato Grosso, o qual através de sua concessionária o SANEMAT - passaria a ter o direito de exploração e implantar e administrar com exclusividade, os serviços de saneamento básico de Rondonópolis, pelo período de 20 anos. Vencido o prazo da concessão, o serviço de saneamento e abastecimento público de água de Rondonópolis, voltou a ser municipal novamente, sendo criada pela Prefeitura Municipal uma nova autarquia originalmente denominada de Departamento de Água e Esgoto (DAE) e que atualmente denomina-se de Serviços de Saneamento Ambiental de Rondonópolis - SANEAR, que a partir do mês de agosto de 1997, reassumiu a responsabilidade desse serviço no município.

Em 2004 o Sistema de abastecimento Público de água de Rondonópolis, operado pelo SANEAR, contava com uma estrutura de 34 poços tubulares para captação de água subterrânea e uma estação de captação de água superficial. Os subsistemas de adução e distribuição de água na cidade, possuía uma extensão de cerca de $412 \mathrm{~km}$, para atender 44.371 ligações das quais 33.897 (76,4\%) possuía hidrômetros instalados. Já a rede de esgoto possuía somente cerca de $230 \mathrm{~km}$ de extensão e atendia apenas $28 \%$ das ligações ativas. (TAB 1)

Tabela 1. Total de ligações ativas de água e esgoto, por categorias em Rondonópolis, 2004.

\begin{tabular}{l|r|r}
\hline Categoria & Água & Esgoto \\
\hline Residencial & 41.671 & 11.437 \\
Comercial & 1.817 & 1.185 \\
Industrial & 30 & 14 \\
Pública & 494 & 156 \\
Social & 359 & 73 \\
\hline Total & 44.371 & 12.865 \\
\hline
\end{tabular}

Fonte: SANEAR, 2004.

Destaca-se o fato de que, tanto o índice de hidrometração das ligações quanto o percentual de ligações com serviço de esgoto, sofreram significativo decréscimo no sistema de abastecimento público de Rondonópolis desde que esse serviço passou a ser novamente municipalizado em 1997. O que indica que houve queda nos investimentos realizados pelo SANEAR no sistema nesse período de 7 anos, em que pese o expressivo aumento do total de ligações (cerca de 36\%).
O sistema de abastecimento público de Água de Rondonópolis operado pelo SANEAR é composto pelos seguintes subsistemas: captação, adução de água bruta, tratamento de água, adução de água tratada, reservação e distribuição.

O subsistema de captação de água bruta é responsável pela captação tanto de água superficial do Rio Vermelho, quanto de água subterrânea dos aqüíferos Furnas e Ponta Grossa que ocorrem no território 
do município de Rondonópolis (CASARIN, 2003).

O sistema de captação de água bruta superficial está baseado nas operações do setor de captação e adução de água bruta superficial que está localizado à margem do Rio Vermelho, no fundo do bairro Colina Verde dentro do perímetro urbano e funciona 24 horas por dia. Ele tem a função de captar a água deste rio e bombeá-la para a Estação de Tratamento de Água (ETA) que fica no bairro Sagrada Família, próximo ao centro da cidade.

Já o sistema de captação de água bruta subterrâneo estrutura-se sobre uma rede de 34 poços tubulares distribuída pelo perímetro urbano de Rondonópolis. Atualmente somente 27 estão em funcionamento, e juntos respondem por mais de $50 \%$ do abastecimento da cidade.

O sistema de tratamento de água bruta é composto pela Estação de Tratamento de Água superficial (ETA) e por sistemas dosadores de cloro, instalados em cada poço tubular.

Construída em 1982, a ETA tem como finalidade fazer o tratamento da água captada superficialmente e funciona 24 horas por dia. $\mathrm{O}$ tipo de tratamento empregado nessa água bruta é o convencional para limpeza de resíduos físicos (com utilização de filtros) e descontaminação biológica através da utilização de produtos químicos como cloro, cal, sulfato de alumino e hipoclorito de sódio.

A água produzida na ETA é responsável por cerca de $50 \%$ do abastecimento da cidade, sendo parte bombeada para um reservatório localizado no Setor Operacional do Jardim Monte Líbano, e parte enviada diretamente para o abastecimento de alguns bairros da cidade.

O subsistema de adução é composto por tubulações responsáveis pelo transporte da água bruta captada no Rio Vermelho para a ETA, bem como por tubulações para transporte de água tratada desta e dos poços tubulares profundos para as unidades de reservação.
O subsistema de reservação de Água Tratada é composto por 6 reservatórios em funcionamento, os quais em conjunto podem armazenar 14.500 .000 litros de água para cidade. Quatro destes reservatórios encontram-se localizados nos bairros Jardim Atlântico, Jardim Buriti, Jardim das Flores e Parque Universitário e juntos somam 4.000.000 de litros de água em reservação.

Na ETA também existe um reservatório apoiado com a capacidade de armazenamento de 3.500.000 litros. E há ainda outro reservatório apoiado, localizado no Bairro Monte Líbano, com capacidade de armazenar 7.000.000 litros de água tratada, que é recebida da estação de tratamento e reenviada para vários bairros da cidade.

O subsistema de distribuição de água tratada corresponde a cerca $270 \mathrm{Km}$ (96\%) da extensão total da rede do sistema de abastecimento público de água de Rondonópolis, sendo composta por cerca de 270 km com tubulações com diâmetros inferior a 100mm, cerca de 107 km com diâmetros entre 100 e 200mm e cerca de $17 \mathrm{~km}$ com diâmetros entre 200 e 300 $\mathrm{mm}$. Essa rede é composta, sobretudo (cerca de 70\%), por tubulações de PVC. Mas também há segmentos de tubulações de ferro fundido, de fofo e ainda cimento amianto (cerca de 32km). (RODRIGUES, 2005)

O município de Rondonópolis possui uma população aproximada de 150.049 habitantes, sendo que a grande maioria dela, 141.660 (ou 94,4\%), reside no seu perímetro urbano (IBGE, 2001). Já a população atendida pelo serviço público de água e esgoto é de 132.000 habitantes, representando, portanto, cerca de 93\% da população total do município.

\section{MATERIAIS E MÉTODOS}

\section{Materiais}

Para verificar a existência de uma possível flutuação sazonal do consumo de água potável distribuída pelo SANEAR em Rondonópolis, utilizouse dados sobre os totais mensais de consumo de água referentes ao período de 1998 a 2003, do cadastro 
comercial do SANEAR.

Já para verificar a variação espacial das perdas físicas no perímetro urbano de Rondonópolis, foi utilizado tanto os dados mensais de produção de água (cadastro operacional), como os dados mensais de consumo de água (cadastro comercial), referentes aos anos de 2000 e 2003, fornecidos pelo SANEAR.

Também foi utilizado um mapa em formato analógico com as zonas de produção e rotas de distribuição de água do sistema de abastecimento público de Rondonópolis, produzido pelo setor operacional do SANEAR, na escala de 1:30.000.

\section{Métodos}

Para verificar a existência de um movimento estacional na série de dados de consumo de água em Rondonópolis, foi preciso remover desta sua tendência de crescimento. Desse modo, optou-se por padronizar os totais mensais de consumo em termos de desvios relativos em relação ao consumo médio anual.

Já para representar tal estacionalidade em termos de consumos médios mensais na série analisada, optou-se pelo cálculo dos índices de variação estacional, obtido pela razão entre a média de consumo de cada mês pela média do consumo anual de água do período analisado.

Para avaliar e espacializar as perdas físicas do sistema de abastecimento público de água de Rondonópolis, primeiro foi preciso compatibilizar, com auxílio dos recursos de geoprocessamento, informações que se encontrava em diferentes unidades espaciais. Ou seja, os dados de Produção de Água que encontravam-se organizados e armazenados em nível de "zonas de produção de água" no cadastro do setor operacional do SANEAR; e os dados de Consumo de Água, que estavam organizados e armazenados em nível de "bairros" no cadastro do setor comercial do SANEAR.

Assim, antes de tudo, foi preciso compatibilizar as informações destes dois planos de informação numa única unidade espacial para poder prosseguir com as análises.

\section{Espacialização dos Dados de Produção de Água no Perímetro Urbano}

Após escanerizar o mapa das "zonas de produção e rotas de distribuição” de água, fornecido

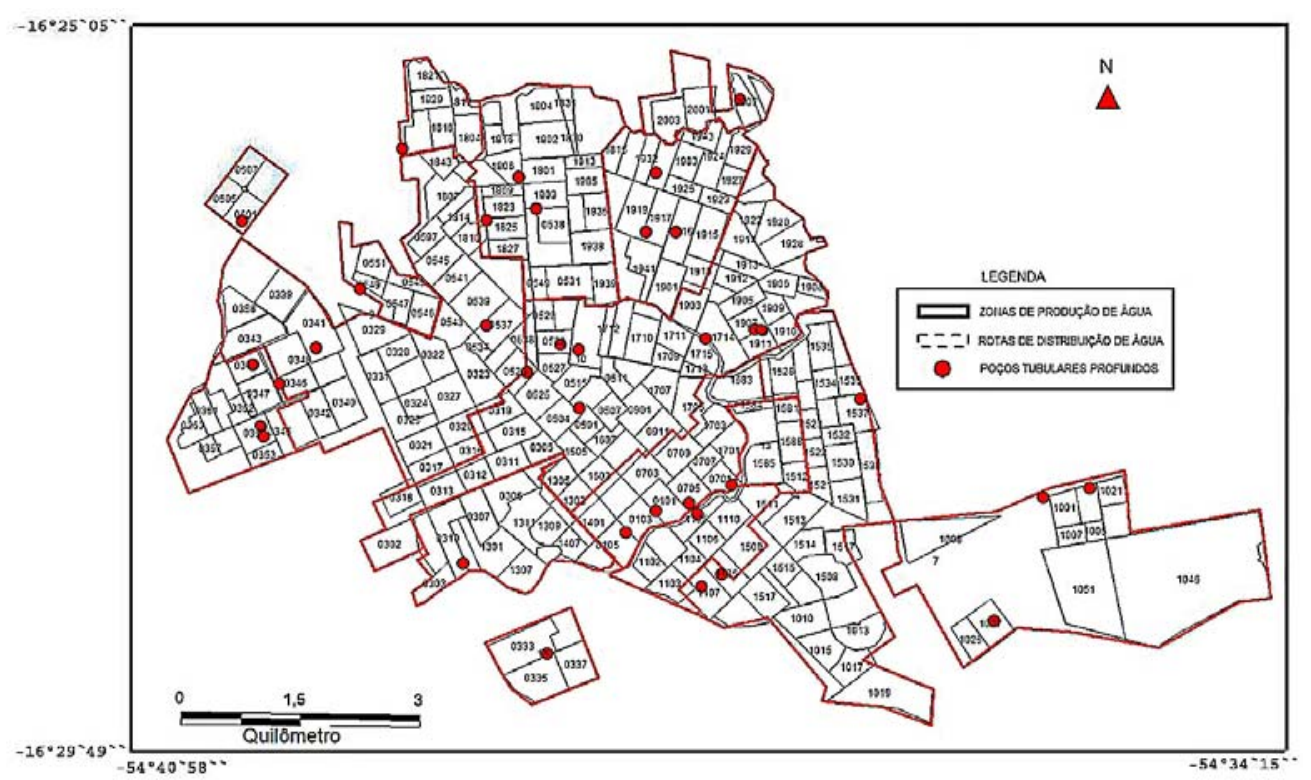

Figura 2. Zonas de Produção, Rotas de Distribuição de Água e Localização dos Poços Tubulares Profundos do Sistema de Abastecimento de Água de Rondonópolis - MT 
em formato analógico pela Concessionária de água de Rondonópolis, o mesmo foi vetorizado para o banco de dados geográfico do estudo, produzido no ambiente do Sistema de Informação Geográfica Mapinfo, dando origem ao plano de informação Zonas de Produção de Água em Rondonópolis. (Fig. 2)

Em seguida, após analisar a consistência dos dados de produção de água (entendida como os volumes de água tratados saídos da ETA e dos Poços Tubulares Profundos), fornecidos em formato Excel pelo SANEAR, chegou-se a conclusão que apenas aqueles relativos aos anos de 2000 e 2003, poderiam ser utilizados como amostras para a avaliação do nível de perdas físicas de água no sistema de abastecimento de Rondonópolis.

\section{Espacialização dos Dados de Consumo de Água no perímetro Urbano}

Os dados de consumo total de água em Rondonópolis (consumos micromedios + consumos estimados) foram importados para o ambiente Mapinfo, a partir de uma base de dados construída sobre um banco de dados SQL, pelo setor de cadastro comercial do SANEAR. Utilizando-se o código das zonas de produção e das rotas de distribuição de água, presentes nos dados das faturas das contas de água desse cadastro, e usando os recursos de gerenciamento de banco de dados do Mapinfo, foi possível agregar tais informações na forma de totais anuais de consumo de água para as unidades espaciais “zonas de produção de água da cidade”.

\section{Avaliação das Perdas de Água no Sistema de Abastecimento de Rondonópolis}

Uma vez ajustadas para a mesma unidade espacial (zonas de produção de água de Rondonópolis) tanto as informações de produção como de consumo de água, bastava apenas implementar no SIG Mapinfo a equação para o cálculo do total de perdas físicas, entendidas como a parcela não consumida da água produzida em cada uma dessas zonas de produção. Por tanto, foi assumido como valor de tais perdas o resultante da subtração do total do volume $\left(\mathrm{m}^{3}\right)$ anual consumido (micromedidos + estimados) do total do volume $\left(\mathrm{m}^{3}\right)$ anual produzido/ distribuído nas zonas de produção, nos anos de 2000 e 2003. E como índice de perdas físicas, o "Percentual de Volumes Não Consumidos” (PVNC) o qual foi determinado pela seguinte equação:

PVNC $=\underline{100 * \text { Volume Produzido }- \text { Volume Consumido }}$ Volume Produzido

\section{RESULTADOS E DISCUSSÃO}

\subsection{Variação Estacional do Consumo de Água em Rondonópolis}

Conforme pode-se observar na figura 3, há

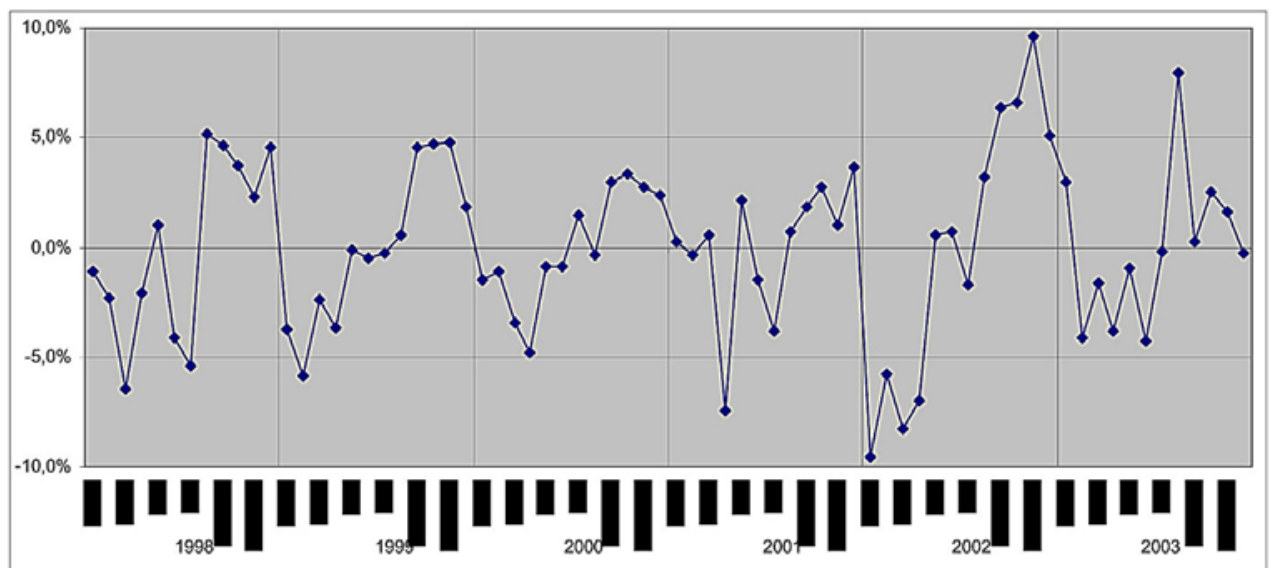

Figura 3. Desvio (\%) dos Totais Mensais de Consumo de Água em Rondonópolis em relação ao Consumo Médio dos Anos de 1998 a 2003 
uma variação estacional no consumo de água em Rondonópolis, sendo que num período de 5 a 6 meses, que oscila entre os meses de julho/agosto a dezembro, verifica-se consumo de água a cima da média anual.

Destaca-se ainda que apesar da de amplitude de variação do consumo de água neste movimento estacional, manter-se entre 5 e $-5 \%$ do consumo médio anual para a maioria dos anos analisados, 0 mesmo pode alcançar maior intensidade (amplitude de até 20\%), conforme observado nos desvios do ano de 2002. (Fig. 3)

Essa variação máxima entre os períodos de maior e menor consumo de água no ano, se aproxima de valores indicados na literatura, onde variações climáticas influenciam no comportamento do usuário no sentido de modificar seu consumo médio de água, apontando-se para uma variação de menos $20 \%$ no período de inverno e de cerca de mais $25 \%$ no período do verão em relação à média anual (LEME apud BRUDEKI, 2005:07).

Contudo, em termos médios, pode-se identificar dois períodos bem destacados no ritmo anual do consumo de água em Rondonópolis. Sendo um com consumos a baixo da média anual, compreendido entre os meses de janeiro a abril, e outro com consumos a cima da média anual, compreendido entre os meses de agosto a dezembro (FIG 4).

Entretanto, ainda não encontrou-se a explicação do por que, dessa variação sazonal do consumo de água de em Rondonópolis. Várias hipóteses estão sendo atualmente investigadas para explicá-la, sendo algumas relacionadas ao ritmo climático (sobretudo a variação das temperaturas e chuvas), outras a dinâmica social e outras ainda, da combinação das duas.

De qualquer modo acredita-se que tal variação sazonal pode estar relacionada com os níveis de perdas físicas, sobretudo àquelas ocorridas na rede de distribuição, uma vez que, com a redução do consumo no período de agosto a dezembro, haverá maior pressão na rede e maior chance de problemas de rompimentos e vazamentos, já que a produção se mantém constate no sistema de Rondonópolis o ano todo. Infelizmente o SANEAR não disponibilizou os dados de serviços de consertos da rede de água de Rondonópolis, que poderiam servir para verificar se tais rompimentos tem maior freqüência no período de janeiro a abril, o que permitiria comprovar tal relação.

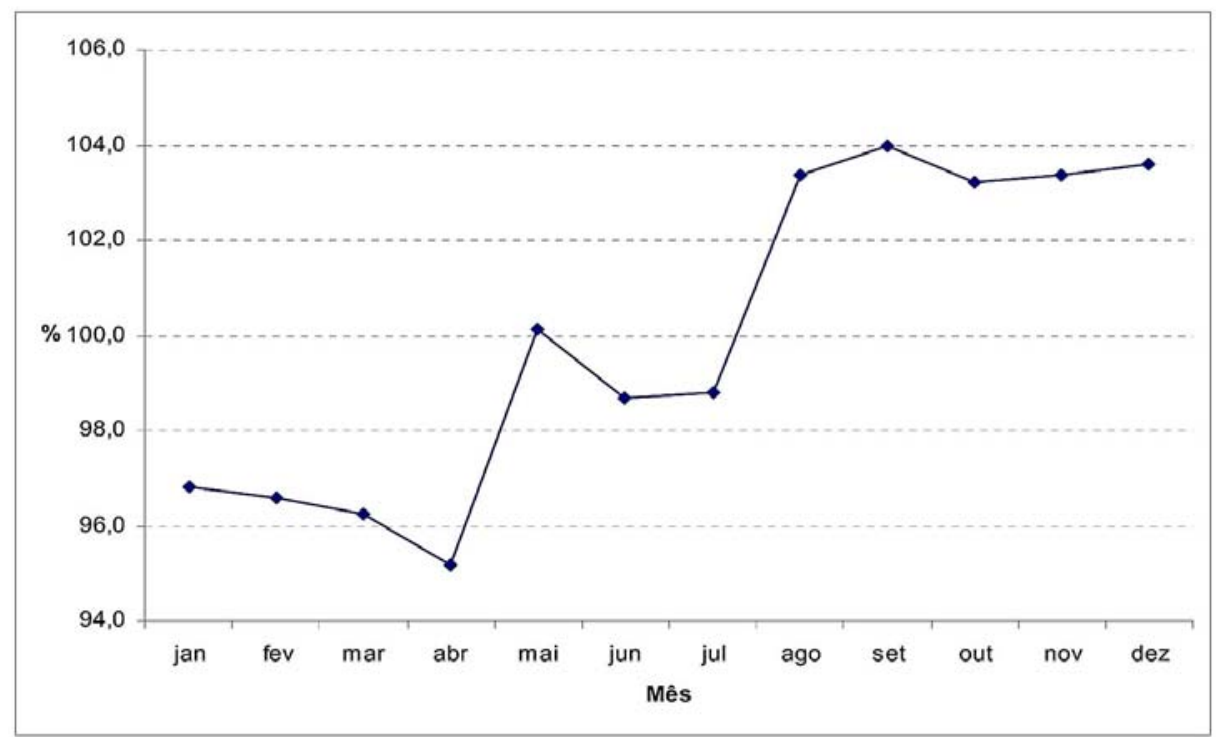

Figura 4. Índices de Variação Estacional do Consumo de Água em Rondonópolis no período de 1998 a 2003 


\subsection{Avaliação e Espacialização das Perdas Físicas de Água do Sistema de Abastecimento Público de Rondonópolis}

Quanto ao aproveitamento da água produzida nas 16 zonas de produção, constatou-se que na maioria delas no ano de 2000 (73\%) e em metade no ano de 2003, o índice de perdas físicas ficou entre 50 e $75 \%$. E em duas delas no ano de 2003 e uma no ano de 2000, o desperdício superou a $75 \%$ da água que produziram. (FIG 5).

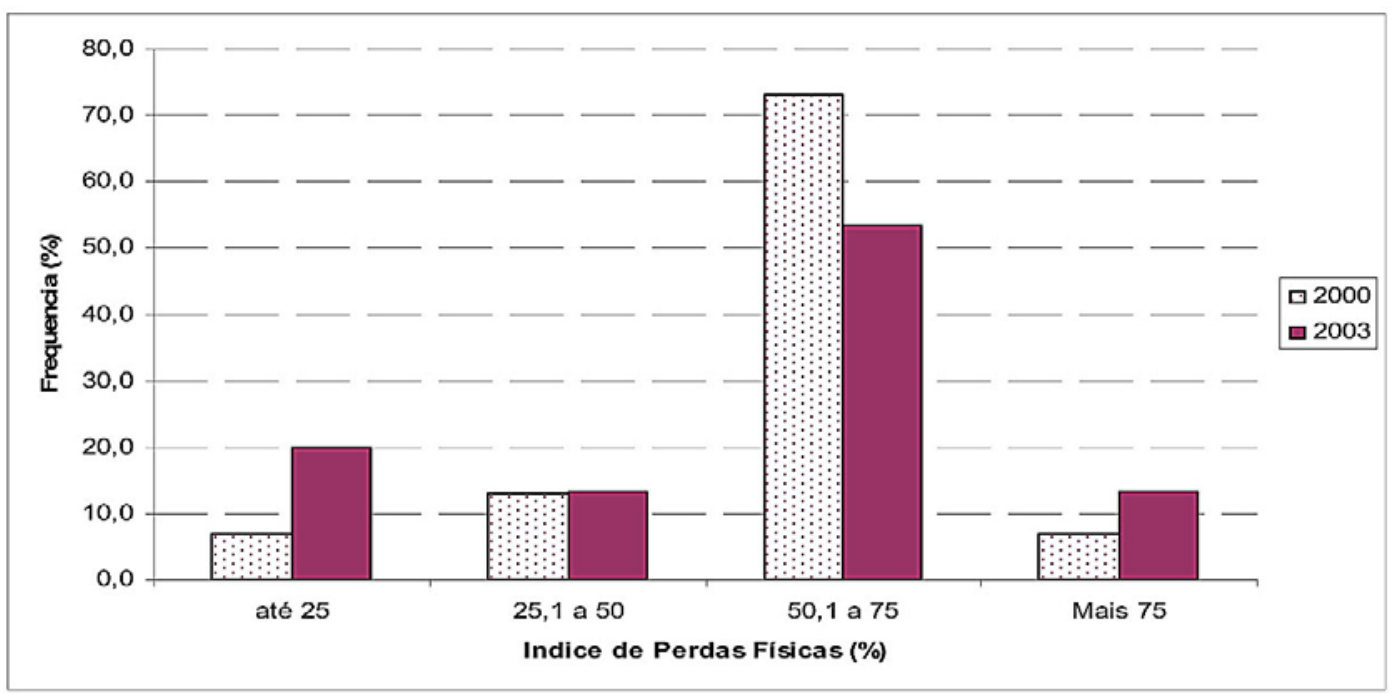

Figura 5. Distribuição do Índice de perdas físicas nas zonas de produção de água de Rondonópolis-MT nos anos de 2000 e 2003

Em termos médios, o índice de perdas físicas de água em Rondonópolis, ficou em torno de 55\% para os dois anos. Valor superior aos índices médios de perdas físicas verificados por Silva (2005:08) em sistemas de abastecimento públicos do Estado do Ceará (36\%), e superiores também a média nacional de perdas de faturamento que é de $40 \%$ para prestadores de serviço de abrangência local, e de 44,1\% para a Região Centro-Oeste (PMSS, 2004:19).

A espacialização desses índices de perdas físicas pelas zonas de produção de água de Rondonópolis, revela que as duas zonas que apresentaram nível de desperdício da água extremamente elevado (a cima de 75\%) nos anos de 2000 e 2003, localizamse no setor norte-nordeste da cidade (FIG 6 e 7), e são os locais mais indicados para se iniciar um projeto piloto de contenção dessas perdas no sistema de abastecimento da cidade.

No ano de 2000, verificou-se apenas uma zona (Vila Rica) com nível de perdas extremamente elevado (entre 77 e 91\%), ou seja, com aproveitamento de menos de $10 \%$ da água nela produzida neste ano. E sete zonas com nível de perdas entre 59 e 77\% (Monte Líbano Pressurizado, Monte Líbano Gravidade, Residencial São José, Vila Goulart, Jd. Ipanema/CA e Jd. Atlântico). E apenas 2 zonas (Vila Operária e ETA/Cidade Alta) com nível de perdas inferior a $41 \%$. (FIG 6)

No ano de 2003, verificou-se duas zonas com nível de perdas entre 72 e 94\% (a zona Monte Líbano Pressurizado e novamente a Vila Rica), e 7 com nível entre 51 e 72\% (Monte Líbano Gravidade, Residencial São José, Vila Cardoso/Centro B, Vila Aurora, ETA/Cidade Alta, Jd Atlântico e Jd Ipanema/ CA). E apenas 3 zonas com nível de perdas relativamente baixos (entre 11 e $30 \%$ ), a zona Vila Goulart, Vila Operária e Conjunto Hab. São José. (FIG 7) 


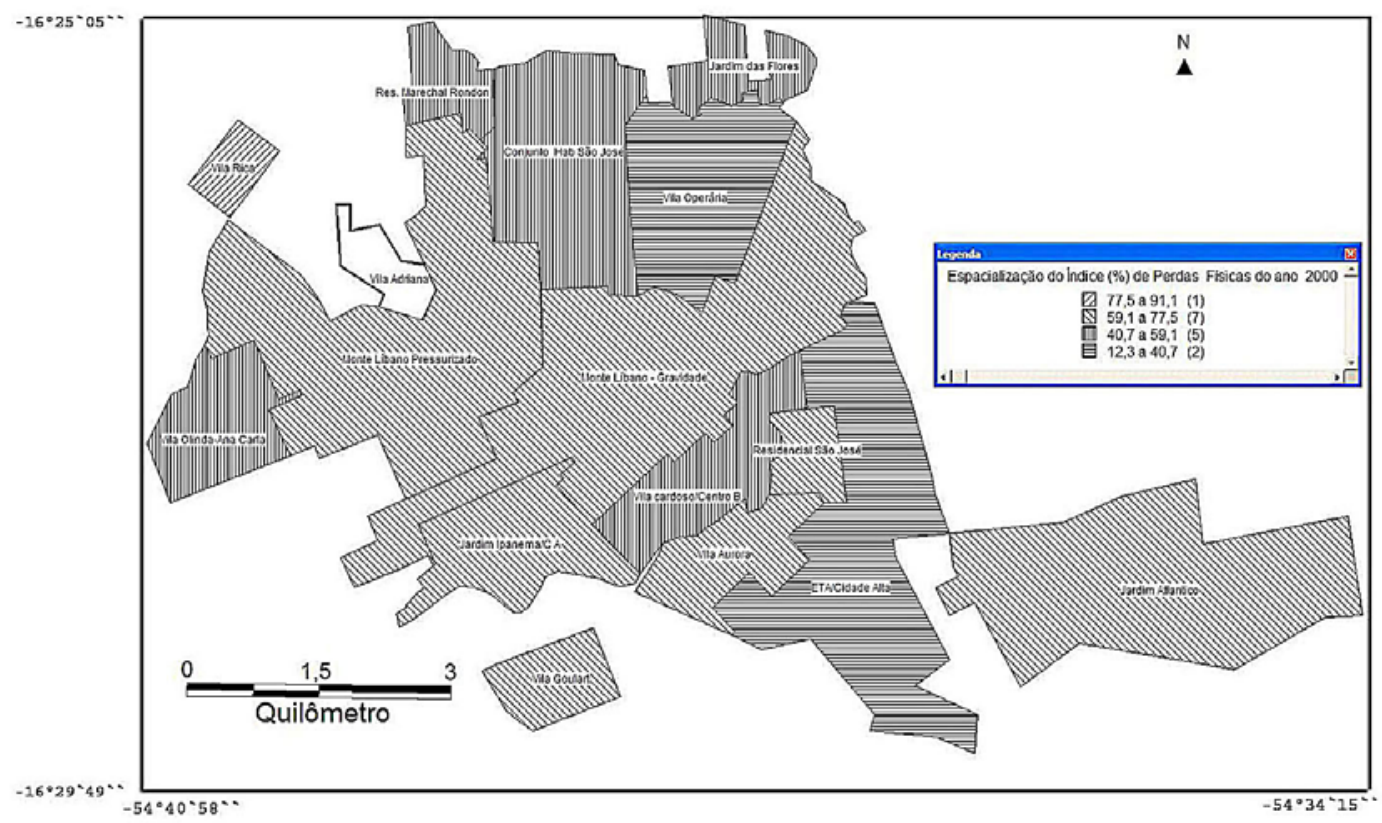

Figura 6. Índice (\%) de Perdas Físicas de água em Rondonópolis no ano de 2000, segundo as zonas de produção

Destaca-se que a zona de produção Vila Rica aparece como uma das zonas de pior desempenho nos dois anos analisados, indicando claramente ser um local emergencial para a atuação do SANEAR no sentido de reduzir o nível de perdas físicas de água no sistema de abastecimento público de Rondonópolis. E, do mesmo modo, as zonas Monte
Líbano Gravidade, Residencial São José, Jd Ipanema/ CA e Jd Atlântico, também figuram nos dois anos como locais com elevado nível de perdas físicas (entre 50 e 70\% aproximadamente), e deste modo, também podendo figurar na lista de lugares prioritários para um plano de redução de perdas neste sistema de abastecimento público de água.

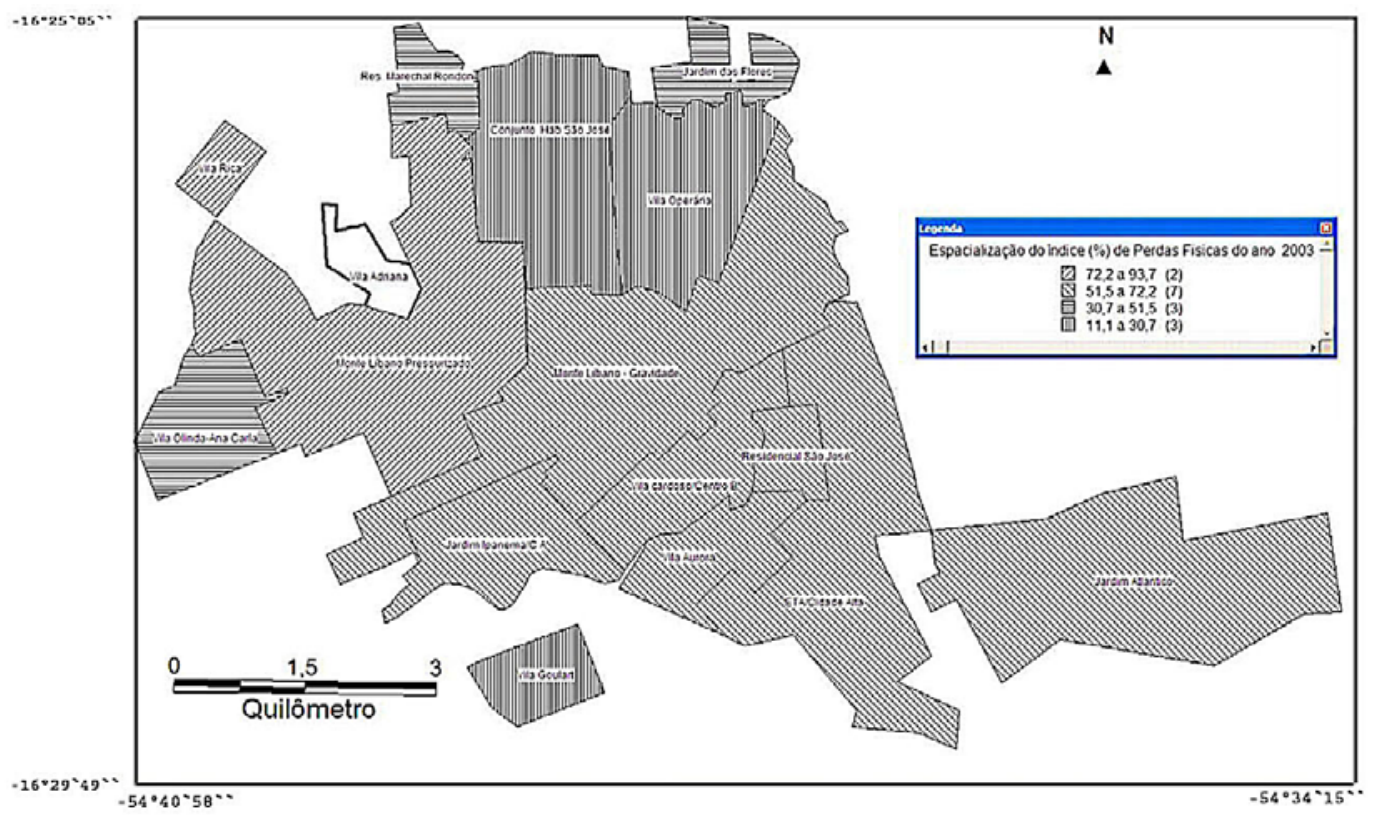

Figura 7. Índice (\%) de Perdas Físicas de água em Rondonópolis no ano de 2003, segundo as zonas de produção 
Taís índices de desperdício, provavelmente decorrentes de vazamentos na rede de distribuição, devem estar relacionados com rompimentos da rede por excesso de pressão ou desgaste de conexões, uma vez que tal rede já apresenta tubulações com tempo de uso superior ao recomendado, sobretudo daquelas zonas de produção que localizam-se mais no centro da cidade, as quais já deviam ter sido substituídas tanto em razão de tempo de utilização quanto pela qualidade dos materiais que são constituídas conforme apontado por Garcia (1995). Pois conforme foi citado no tópico 3 deste artigo, cerca de $32 \mathrm{Km}$ de tubulações da rede de água do centro da cidade, que é a rede mais antiga de Rondonópolis, é constituída por tubulações de cimento amianto (RODRIGUES, 2005) que conforme relatos de funcionários dos setor operacional do SANEAR, apresentam muitos problemas de rompimentos.

A espacialização das perdas físicas de água do sistema de abastecimento público de Rondonópolis em termos de valores absolutos das perdas $\left(\mathrm{m}^{3}\right)$, revelou que nos anos de 2000 e 2003, estas alcançaram valores extremamente elevados (entre 780.000 e $2.700 .000 \mathrm{~m}^{3}$ ), em 4 zonas de produção tanto no ano 2000 como em 2003. E valores entre 240.000 e $788.000 \mathrm{~m}^{3} \mathrm{em} 5$ zonas de produção no ano 2000 e em 3 no ano de 2003 (FIG 8 e 9). Ou seja, as perdas de água alcançaram valores bastante elevados na maioria das zonas de produção de água da cidade no ano de 2000 e em praticamente $50 \%$ delas no ano de 2003.

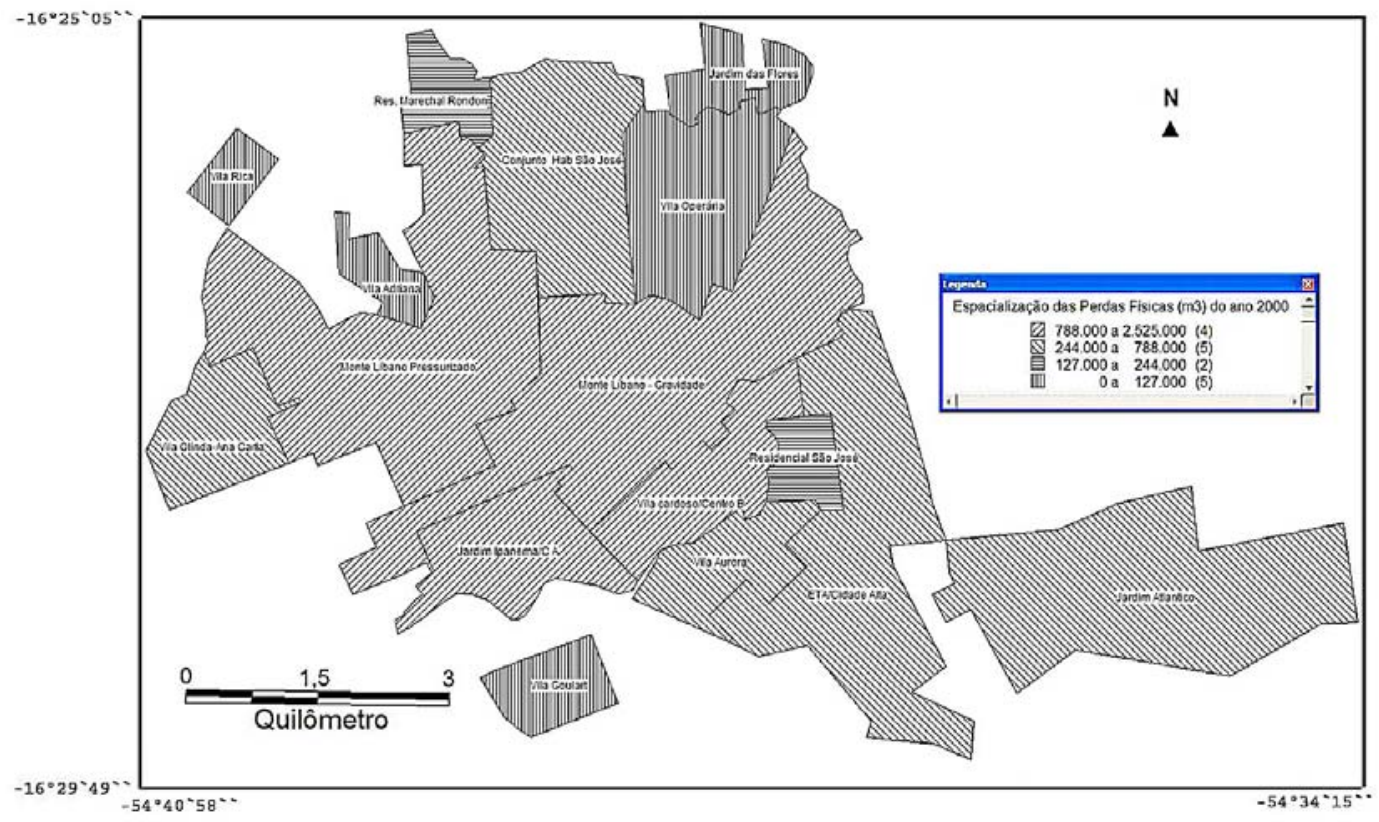

Figura 8. Perdas Físicas $\left(\mathrm{m}^{3}\right)$ da água produzida em Rondonópolis no ano de 2000, segundo as zonas de produção

Conforme observa-se nas figuras 8 e 9 , as zonas de produção com os maiores valores absolutos de perdas de água, concentram-se principalmente na região mais centralizada do perímetro urbano, onde localiza-se os segmentos da rede de distribuição com tubulações mais velhas.

Já no caso das zonas de produção com va- lores elevados de perdas e localizadas nos setores mais periféricos da cidade, o problema pode estar relacionado tanto a rompimentos das tubulações da rede, principalmente em decorrência de mau gerenciamento de pressão na mesma, influenciados tanto pela variação estacional do consumo que foi demonstrada, como pela variação diária nos picos de consumo de água na rede, mas também, devido a furtos 


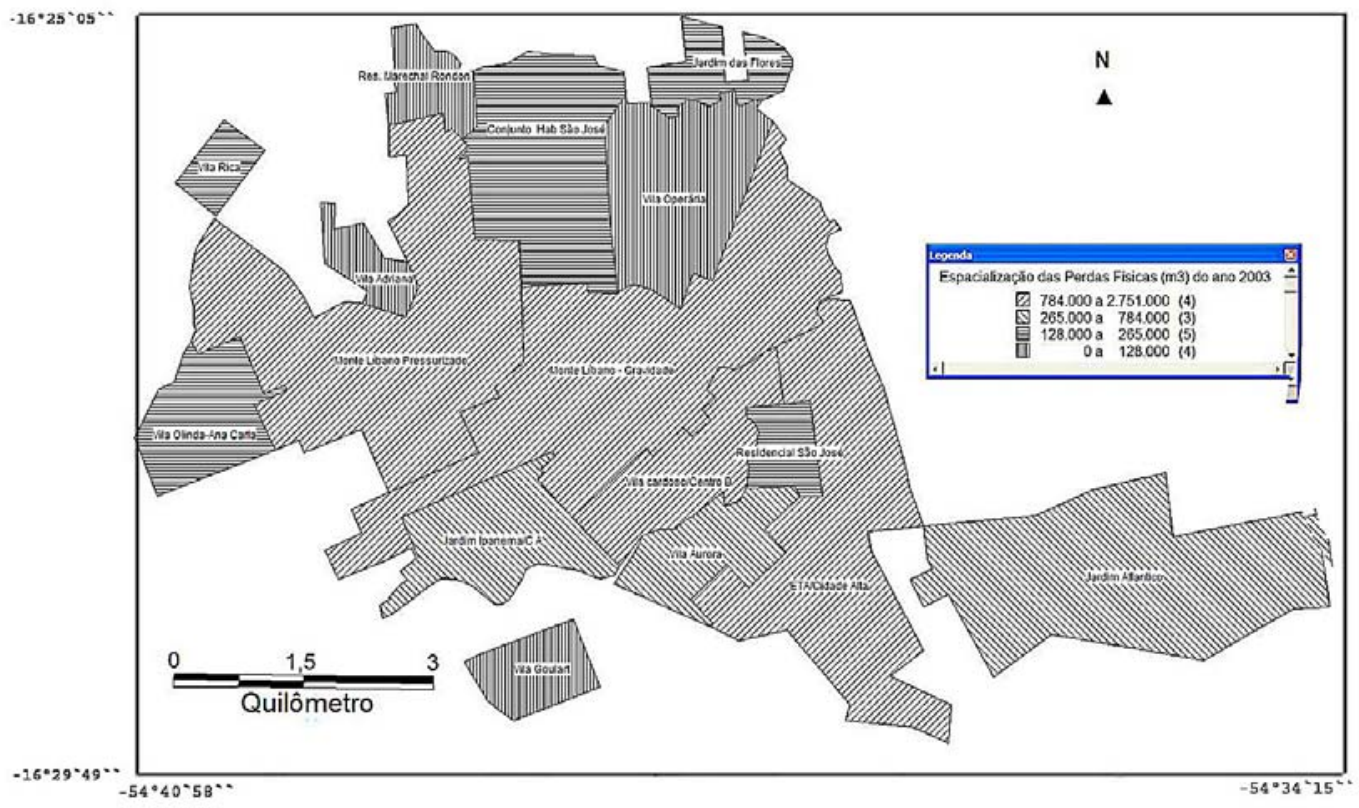

Figura 9. Perdas Físicas $\left(\mathrm{m}^{3}\right)$ da água produzida em Rondonópolis no ano de 2003, segundo as zonas de produção

de água através de ligações clandestinas ("gatos”). de expansão/ocupação urbana, algumas delas in-

Tais furtos são realizados por moradores tanto de bairros já regularizados e onde já há a instalação dos aparelhos de micromedição do consumo (hidrômetros), como por moradores de novas áreas clusive irregulares. Em visita a uma dessas áreas, que fica vizinha ao Jardim Ana Carla, foi observado várias mangueiras ligadas clandestinamente à rede de distribuição de água da cidade, algumas inclusive, apresentando vazamentos. (Foto 01)

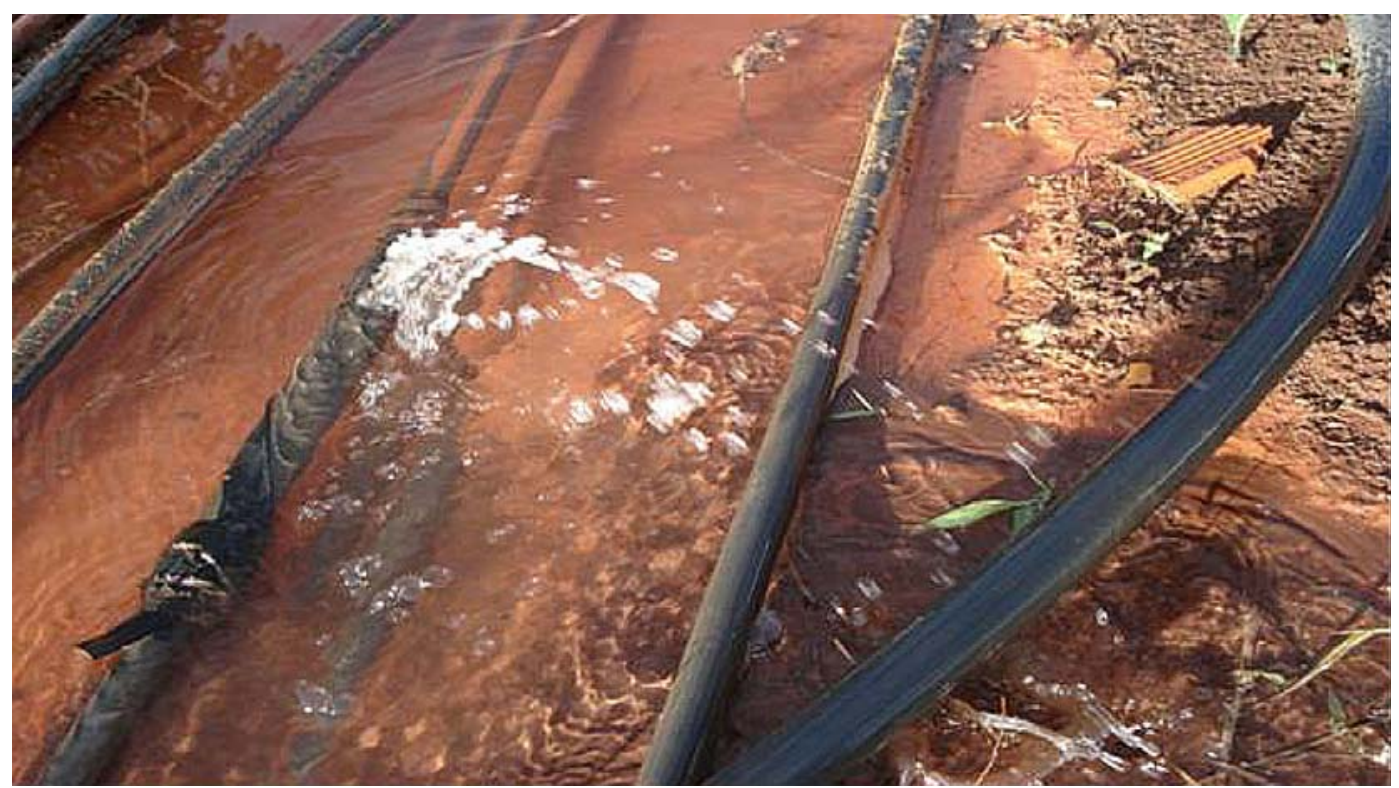

Foto 1. Vista Parcial de ligações clandestinas de água em área de expansão/ocupação urbana vizinha ao Jardim Ana Carla em Rondonópolis - MT, inclusive com ocorrência de um vazamento Nota: Fotografia de Francisco Vieira da SILVA, 20/03/2007 


\section{CONCLUSÕES}

Pelos resultados encontrados nesse estudo, pode-se verificar que o sistema de abastecimento público de água de Rondonópolis apresenta baixa eficiência no aproveitamento da água na maioria das suas zonas de produção, como ficou demonstrado nos mapas do dois anos analisados. Deste modo, tal metodologia permite àqueles municípios que não possuem macro-medidores na rede do seu sistema de abastecimento público de água, verificar o nível de perdas do mesmo e quais são os locais prioritários para a concessionária atuar no sentido de combater tais perdas.

O fato desse sistema apresentar baixa eficiência, além de caracterizar grave desperdício deste precioso recurso natural, ainda deve promover reflexos negativos na qualidade do serviço de abastecimento que é prestado a população (muitas interrupções e intermitências no fornecimento), a qual, em última instância, acaba sofrendo com a falta de água para suas necessidades básicas. Sobretudo a população mais pobre, a qual muitas vezes nem possui caixas d'água para armazenar a pouca água que recebe e assim amenizar esse problema.

Sobre a participação do ritmo climático na ocorrência desses problemas, ainda é preciso avançar mais nas analises, mas de qualquer modo, o fato de haver um período de menor consumo como ficou demonstrado, certamente deve influenciar na pressão da rede, uma vez que os totais de produção de água são constantes durante o ano, e contribuir para rompimentos da mesma. Contudo, tal hipótese só poderá ser confirmada quando os dados sobre os rompimentos e serviços de reparos da rede forem disponibilizados pelo SANEAR o que até o presente momento, apesar de terem sido solicitados várias vezes, ainda não ocorreu.

\section{REFERÊNCIAS BIBLIOGRÁFICAS}

BRANCO, S. M. Água. Meio Ambiente e Saúde. In: REBOUÇAS, A. da C.; BRAGA, B.; TUNDISI, J. G. Águas do Brasil: capital ecológico, uso e conservação. $2^{\circ}$ ed. São Paulo:Escrituras Editora, 2002. cap. 7 p. $227-248$

BRASIL. Ministério do Planejamento e Orçamento. Secretaria Nacional de Política Urbana. Programa Nacional de Combate ao Desperdício de Água. Documento Técnico de Apoio $\mathbf{n}^{\circ}$ A2: Definição de Perdas nos Sistemas Públicos de Abastecimento. Brasília:MPO-SEPURB-DESAN, 1998. 70p.

BRASIL. Ministério do Planejamento e Orçamento. Secretaria Especial de Desenvolvimento Urbano/ Secretaria de Política Urbana. Programa Nacional de Combate ao Desperdício de Água. Documento Técnico de Apoio no A3: Caracterização da Demanda Urbana de Água. Brasília: MPO-SEPURBDESAN, 1999. 49p

CASARIN, J. C. Qualidade da água superficial e subterrânea na área urbana de Rondonópolis-MT. 2003. 112 f. Dissertação (Mestrado em Ecologia e Conservação da Biodiversidade). Departamento de Geologia/ Universidade Federal de Mato Grosso. Cuiabá, 2003.

GARCIA, A. DE O. O (des) Abastecimento de água em Rondonópolis - MT: Falta de Água? 1995. 79f. Monografia (Especialização em Geografia) Departamento de Geografia/Universidade Federal de Mato Grosso, Rondonópolis, 1995.

HESPANHOL, I. Água e Saneamento Básico uma visão realista. In: REBOUÇAS, A. da C.; BRAGA, B.; TUNDISI, J. G. Águas do Brasil: capital ecológico, uso e conservação. $2^{\circ}$ ed. São Paulo: Escrituras Editora, 2002. cap. 8 p. 294-304

INSTITUTO BRASILEIRO DE GEOGRAFIA E ESTATÍSTICA - IBGE. Censo Demográfico 2000. Rio de Janeiro:IBGE, 2001

LEME, F. P. Engenharia do saneamento ambiental. Rio de Janeiro: LTC - Livros Técnicos e Científicos. 1982 apud BRUDEKI, N. M. Expansão estrutural como possibilidade de uma universalização dos serviços de água e esgoto no Estado do Paraná 
até 2020. 2005166 f. Dissertação (Mestrado em Gestão Urbana) - Pontifícia Universidade Católica do Paraná. Curitiba, 2005.

MIRANDA, E. E de. A água na natureza e na vida dos homens. Aparecida:Idéias e Letras, 2004. 141p.

PROGRAMA DE MODERNIZAÇÃO DO SETOR DE SANEAMENTO. Sistema Nacional de Informações sobre Saneamento. Diagnóstico dos Serviços de Água e Esgotos - 2003. Brasília: MCIDADES.SNSA, 2004

PROGRAMA DE MODERNIZAÇÃO DO SETOR DE SANEAMENTO. Sistema Nacional de Informações sobre Saneamento - Visão Geral da Prestação dos Serviços de Água e Esgotos - 2004. Brasília: MCIDADES.SNSA, 2005.

RODRIGUES, J. S. Mapeamento digital da estrutura de produção, armazenamento e distribuição de água do sistema de abastecimento público de Rondonópolis. CNPq/Universidade Federal de Mato Grosso, 2005. 22 p. Relatório de Pesquisa

SILVA, F. C. et al. Panorama de perdas em sistemas de abastecimento de água. In: SIMPÓSIO DE RECURSOS HÍDRICOS DO NORDESTE, 7., 2004, São Luis. Anais... São Luis: ABRH, 2004. 1 CD-ROM apud SILVA, F. J. A. da. Perda de Água em Sistemas Públicos de Abastecimento no Ceará. Rev. Tecnol., Fortaleza, v. 26, n. 1, p. 1-11, jun. 2005

SILVA, F. J. A. da. Perda de Água em Sistemas Públicos de Abastecimento no Ceará. Rev. Tecnol., Fortaleza, v. 26, n. 1, p. 1-11, jun. 2005

TUROLLA, F. A. Política de saneamento básico: avanços recentes e opções futuras de políticas públicas. Brasília, DF: IPEA, 2002. (Texto para discussão n 922) apud SILVA, F. J. A. da. Perda de Água em Sistemas Públicos de Abastecimento no Ceará. Rev. Tecnol., Fortaleza, v. 26, n. 1, p. 1-11, jun. 2005. 